62

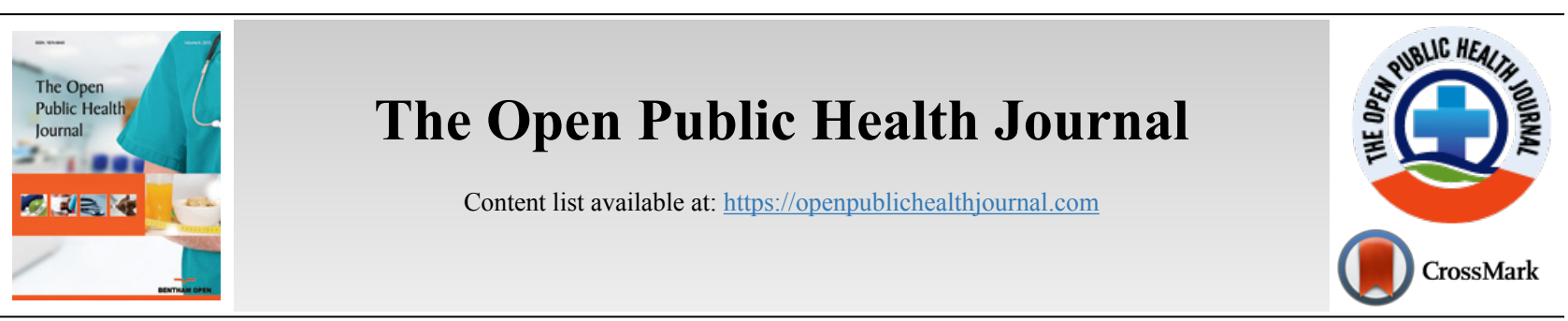

RESEARCH ARTICLE

\title{
Effect of Stress Management Training for the Elderly in Rural Northern Thailand
}

Monchanok Choowanthanapakorn ${ }^{1}$, Katekaew Seangpraw ${ }^{2, *}$ and Parichat Ong-artborirak ${ }^{3}$

${ }^{1}$ School of Public Health (Applied Thai Traditional Medicine), University of Phayao, Phayao 56000, Thailand

${ }^{2}$ School of Public Health (Community Health), University of Phayao, Phayao 56000, Thailand

${ }^{3}$ Faculty of Public Health, Chiang Mai University, Chiang Mai 50200, Thailand

\begin{abstract}
:
Background:

Stress management is an important health promotion activity for elderly people.

Objective:

This research aimed to study the effect of stress management training program on the knowledge and stress management skills of elderly living in the rural community of northern Thailand.

Methods:

This was a quasi-experimental study. The elderly living in rural northern part areas of Thailand were recruited for the study. Multi-stage random sampling was employed to select participants. Seventy-two elderly people were assigned to the intervention group. Participants received stress management training, including knowledge, meditation, and self-practice massage. Interview questionnaires were used as a research instrument in the process of data collection. An independent t-test was employed to compare mean scores between the two groups. Three different time periods were examined using repeated measures ANOVA, test with a significant level of 0.05 .
\end{abstract}

Results:

After the program, there were statistically significant differences in mean scores of knowledge and stress management between the intervention and the control group. The mean scores of knowledge and stress management of the intervention group were higher than the control group (pvalue $<0.05$ ), and the level of stress of the elderly in the intervention group had decreased within and between groups after the follow-up (pvalue $<0.05)$.

Conclusion:

Stress management training program is effective in developing knowledge and stress management skills and helping reduce stress for the elderly living in the rural community of Thailand. This program should be applied to reduce stress and to improve quality of life among other age groups.

Keyword: Stress management training, Stress, Elderly, Thailand, Knowledge, Control group.

Article History Received: October 16, 2020

Revised: January 03, 2021

Accepted: January 16, 2021

\section{INTRODUCTION}

The increase in the aged population is one of the most significant economic, social, and health challenges in the current century $[1,2]$. People aged 60 years and over will possibly have a risk of having one or more chronic diseases due to age-associated diseases [2]. Their emotions are easy to

\footnotetext{
* Address correspondence to this author at the School of Public Health (Community Health), University of Phayao, Phayao 56000, Thailand; Tel: +66-54-46666; E-mail: eungkaew@gmail.com
}

change due to fear of being abandoned and lack of selfconfidence. They experience a decline in health, leading to over-thinking, stress, and depression [3 - 5]. In 2008, there were approximately 11 million elderly people aged 60 years and above (16.5\%) of all the population in Thailand. Moreover, it is expected to increase 5 percent per year, leading to the excessive number of elderly population $[6,7]$. According to the Department of Mental Health in Thailand, stress among the Thai population increased from $11.7 \%$ in 2012 to $16.3 \%$ in 
2016 [8]. Phayao province is located in the northern part of Thailand. The situation of the elderly showed the proportion of elderly people had increased from $16.1 \%$ in 2017 to $18.5 \%$ in 2018 in the province $[6,7]$. Based on the screening data of patients who received health service at the public hospitals, it was found that $34 \%$ of elderly patients experienced mental health problems, including stress $(22.0 \%)$ and depression $(25.0 \%)$ [9]. The main factors leading to stress among the elderly were chronic diseases, including hypertension, diabetes, and cancer; other factors were insomnia, social, family, and economic problems, mainly debts [9]. Stress can alter health functions especially in the circulatory system. If a person is living in a stressful condition for a long period of time, it can cause heart and kidney failure and eventually lead to death [10, 11].

Stress management intervention is defined as techniques and programs that are designed to help the elderly modify their appraisal of stressful situations or deal more effectively with the symptoms of stress, or both [8, 12, 13]. In addition, literature reviews show that stress management intervention has an important process and strategy for elderly people to cope with stress and continue to manage stress effectively [12]. The ability to cope with stress should be appropriated for the physical functions and way of life of an individual [13]. The activities should be suitable for the elderly; for instance, some physical exercises and relaxation activities, including meditation and relaxation massage $[12,13]$. There are various kinds of intervention techniques and programs such as cognitive-behavioral training, personalized feedback based on systematic assessment, meditation, relaxation training, and physical fitness training $[13,14]$. There are reported studies on meditation with a deep breathing exercise and Thai traditional medicine with Thai massage together; with this knowledge training, the intervention helps the elderly manage their stress and understand the mechanism of the physical body leading, to correct ways of self-stress management [12, 13]. Several studies have shown that self-relaxing massage can help increase the flexibility of muscles and reduce stress from certain health conditions [13 - 16]. Moreover, body massage is one of the relaxation methods to reduce muscle pain and stress [13 - 16]. A study shows relaxation massage can directly affect many physical functions such as the sympathetic nervous system, circulatory system, and metabolic system [16, 17]. Relaxation of muscles reduces the stimuli perception of the alpha and theta brain waves, which helps a person remain calm and relax $[16,17]$. In addition, literature reviews show that meditation can cause changes in chemicals in the body leading to an increase in relaxation, better metabolic functions, lower blood pressure, and an increase in neurotransmitters in the brain. This is consistent with the study that found meditation practice can help lower blood pressure levels and reduce stress among hypertension patients $[11,18,19]$. There are a few studies on stress management using massage therapy among the elderly $[10,15]$. Therefore, this study applied the theory of self-care behavior [20] in the intervention activities. Self-care is the process of taking care of one's health in order to prevent illnesses and maintain physical health in good condition. It helps to promote health within the community networks [20]. The objective of this research was to study the effect of stress management training program on the knowledge and stress management skills of elderly living in the rural community of northern Thailand. After the program, elderly people should be able to manage stress on their own by applying a form of integrated knowledge from training, meditation, and selfrelaxation. It also aimed to promote health and self-care behavior among the elderly. As a result, elders will be able to increase their efficiency in taking care of themselves, managing and reducing stress systematically and continuously in their daily lives.

\section{MATERIALS AND METHODS}

\subsection{Sample and Setting}

This study was quasi-experimental research using the intervention and the control groups. Participants were elderly aged 60 years or older living in Phayao province. They were screened using a self-assessment stress test applied from Suanprung Hospital's instrument (SPST-20) [21, 22] from the Ministry of Public Health, Thailand. It is suitable in the context of elderly people living in the community [21, 22]. The inclusion criteria were: participants who received stress scores at a minimum from moderate level (scores of 25-42) [21, 22] aged between $60-75$, both male and female; never been treated by any drugs or alternative medicine within 1-month of recruitment; no hearing, speaking or sighting problems; living in the area of study; willing to participate throughout the program.

The sample size was calculated using the effect size from the mean scores of two groups based on the previous research [23]. The calculation retrieved from the formula [24], the interpretation delta (d) estimates the magnitude influence from the mean score retrieved calculated [25] with the Alpha $=0.05$, Power $=0.80, d=0.5$. According to the calculation and the additional $10 \%$ of dropout rate, the total number of sample size was 144 elderly, 72 participants for each group. The duration of the study started from October 2017 to March 2018 in the rural area of Muang District of Phayao province, Thailand.

Multi-stage random sampling was employed to select the study area with the homogenous characteristics using the drawing technique. Two sub-districts were randomly selected. Ban Tum sub-district was selected for the intervention group, and Ban Tom sub-district was selected for the control group. One village within one sub-district was selected using a random sampling technique. These two villages were approximately 40 kilometers distant from each other. With the distance, there could be prevention of the contamination of information between two groups. Participants were selected using simple random sampling without replacement, as seen in Fig. (1). 


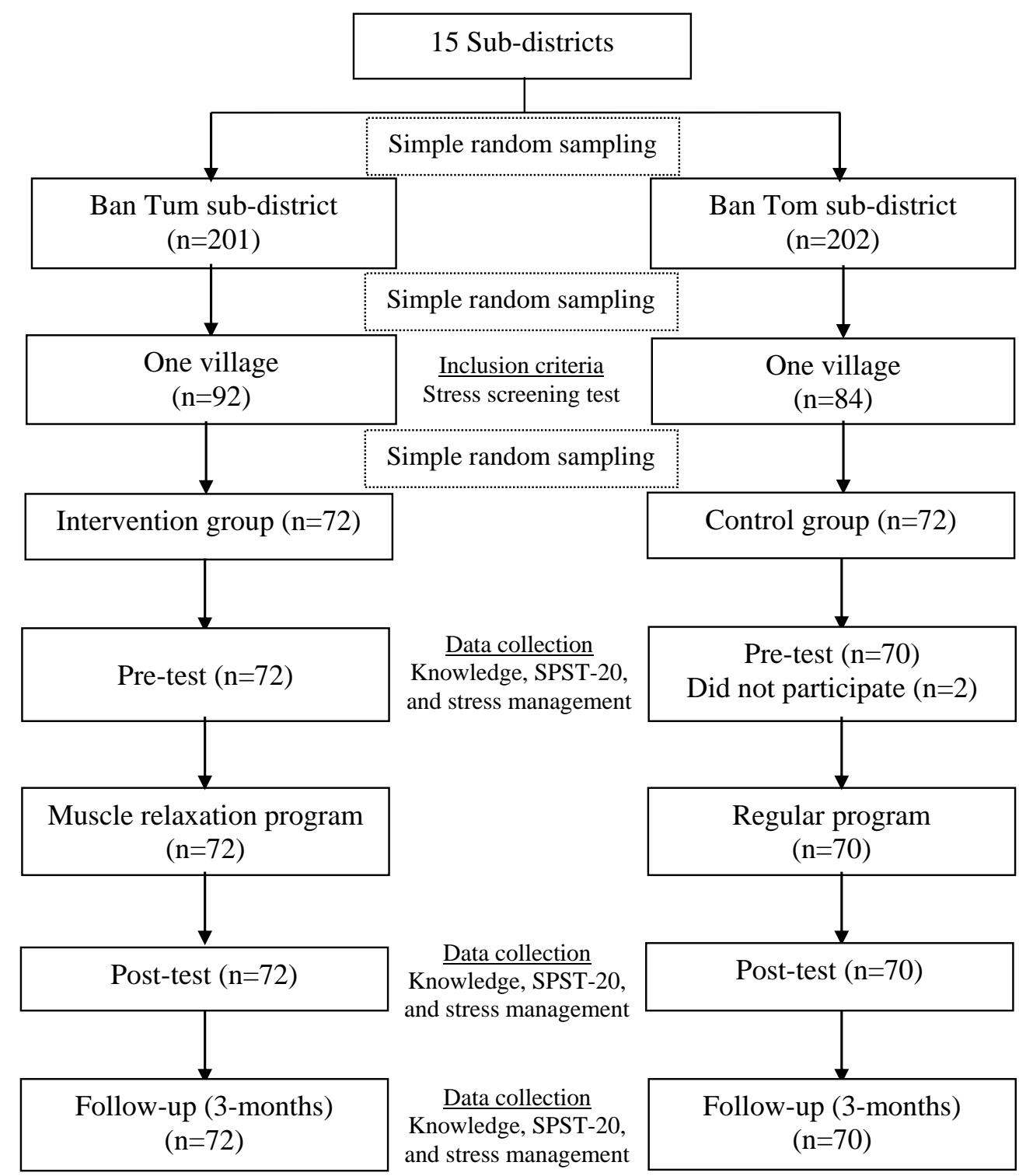

Fig. (1). Participant flow chart.

\subsection{The Tool of Data Collection}

The questionnaires created by the researcher were used to collect quantitative data. They were divided into four parts: Part 1.) General demographic information questionnaire which included age, gender, education, income, employment, and health conditions. Part 2.) The knowledge questionnaire which consisted of 10 items [22]. There were two choices for participants to select: a correct answer is equal to 1 point, and a wrong answer is equal to 0 points. Part 3.) Stress management [22] questionnaire which consisted of 10 items. The researcher applied the questionnaire based on Pender's theory and created it to be suitable in the context of elderly living in the rural community [20, 22]. Rating score was used for this questionnaire which included 4 choices: $1=$ Never, $2=$ Rarely, 3 = Sometimes, and $4=$ Regularly. Part 4.) The stress screening test was applied from Suanprung Stress Test-20 (SPST-20) [13, 21, 22] which consisted of 20 items. The test asked about the events that happened within the last 3 months. Participants were asked about the events occurred, how they felt, and how they responded to the events. The level of measurement was an interval scale, and the scoring was a rating scale. There were four choices including Never $=1$, Sometimes $=2$, Often $=3$, and Regularly $=4$. The questionnaires were examined for content validity by 2 mental health professionals. The questionnaires were re-checked and improved before being used in a pilot study among 30 participants living in San Pa Muang district. The Cronbach's Alpha coefficient of the questionnaires of parts 2, 3, and 4 were $0.79,0.80$, and 0.82 , respectively.

\subsection{Data Collection Procedure}

The stress management training intervention for the elderly was applied from the theory of self-care behavior [20]. The preparation process included the recruitment of research 
assistants from the field of Applied Thai Traditional Medicine. A total of 10 research assistants, currently studying in the third year of university, were recruited. They passed pre-clinic level from the Educational Institution of Applied Thai Traditional Medicine Council before participating in the study. Two professional health personnel, including a massage with a license to practice Thai traditional medicine from the Ministry of Public Health and a lecturer in the field of Applied Thai traditional medicine, were recruited for lecturing and assisting research program for a day, with the participation duration of 6 hours. Participants could use it for self-practice when stressed and record their performance at least 1-2 times a day (morning and evening sessions). The duration ran for 12 weeks, performed once a week.

Week 1: The stress management training program consisted of 2 parts: The first part of the stress training program focused on warm-up by relationships and providing knowledge $[20,26]$. The activities included watching a video regarding stress conditions, health effects of stress, causes and symptoms of stress, stress level, and stress management provided by the researching team.

Week 2-8: The second part of the stress management training program consisted of 2 main activities. (a) Meditation activity integrated with the concept of alternative medicine, which connects mind and body applied from science-based theory [19]. This type of activity helps to relax the body and mind. It stimulates the increase of melatonin, which is an antioxidant chemical that helps to balance the immune system. (b). Stress-management using self-practice massage training was applied from Thai traditional massage [26, 27].

Moreover, the researcher provided additional knowledge regarding Thai traditional medicine. Information was provided as follows: 1). Heat compressing using Thai herbal compress ball (250 g.) which consisted of Thai herbs including turmeric, cane, curcumin, lemongrass, vine, bergamot skin, tamarind leaves, sompoi leaves, camphor, and borneo camphor [27, 28]. Participants should use heat compressing Thai herbal compress ball after practicing self-massage for 10 to 15 minutes. 2). Participants should not eat certain food such as sticky rice, bamboo shoot, and meat. They should not drink alcohol or take a pain reliever before doing self-practice massage. This was to prevent stomachache while having a massage [27 - 31]. Participants had to record every activity in the notebook every day. In case the participants forgot to record it, a village health volunteer would visit home and remind them to perform the activity every day until the end of the intervention program. The stress management training program is summarized in Table 1.

Week 9-12: The follow-up program consisted of visiting the elder's house (twice a week, 60 minutes each time) and making one phone call per week for a check-up. The research team encouraged the elderly to perform self-stress management regularly; this helped to reduce their cost of health service and time. For the control group, elderly participants received a massage handbook provided by the local health center. The total program ran for 12 weeks, and the follow-up was done after 3 months of training in order to observe the changes in elders' behaviors. Both groups used the same assessment test questionnaires provided by the researcher.

Table 1. Research procedures.

\begin{tabular}{|c|c|c|}
\hline Week & Intervention & Evaluation \\
\hline $1^{\text {st }}$ week & $\begin{array}{l}\text { The stress management training program divided into } 2 \text { parts; } \\
\qquad \begin{array}{l}1 \text { part: } 2 \text { activities }(2 \mathrm{hrs} \text {.); } \\
\text { - warm up by relationships }\end{array} \\
\text { - provide video knowledge by health effects of stress, causes and symptoms of stress, stress level, } \\
\text { and stress management }\end{array}$ & - observing participants \\
\hline $2^{\text {nd }}-8^{\text {th }}$ weeks & 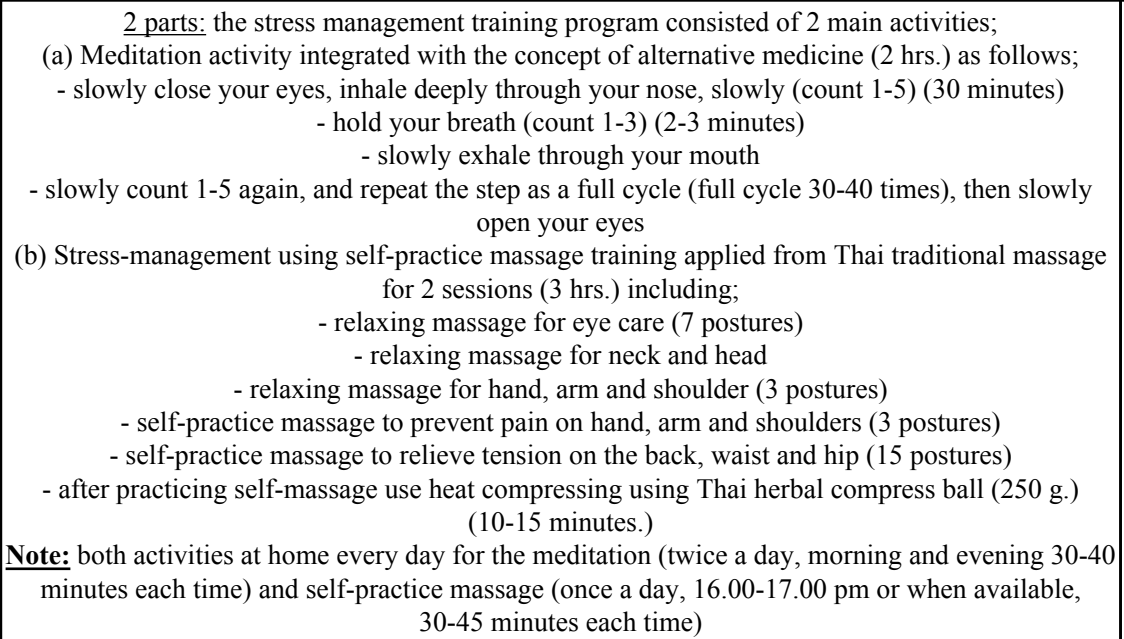 & $\begin{array}{l}\text { - self-practice by observing } \\
\text { participants } \\
\text { - self-regulation by record activity } \\
\text { in the notebook every day }\end{array}$ \\
\hline
\end{tabular}


(Table 1) contd.....

(Table 1) contd.....
\begin{tabular}{|c|c|c|}
\hline Week & Intervention & Evaluation \\
\hline $\begin{array}{c}9^{\text {th }}-12^{\text {th }} \\
\text { weeks }\end{array}$ & $\begin{array}{c}\text { Home visit care to remind participants to follow the program and stimulate the motivation to } \\
\text { practice (twice a week, } 60 \text { minutes each time); }\end{array}$ & - observing participants \\
& $\begin{array}{c}\text { about their problems } \\
\text { - short discussion about knowledge, stress management, set or assess self-regulation, and the elders }\end{array}$ & - mobile phone follow up on the encouragement (1 time per week) \\
\hline
\end{tabular}

\subsection{Statistical Analysis}

Data were analyzed by SPSS Version 20, licensed from the University of Phayao (SPSS Inc., Chicago, IL, USA). Descriptive statistics were used to analyze general information. Independent t-test and Chi-square test were used to identify differences in the characteristics of the elderly at baseline of the intervention and the control groups. A repeated measure ANOVA was used to test the effects before and after the program. All analyses used a 95\% CI, and the level of significance for all the statistical tests was set at p-value $<0.05$.

\section{RESULTS}

\subsection{Sample Characteristics}

In this study, a total of 142 elderly participants ( 72 in the intervention group and 70 in the control group) were similar. The findings showed that the mean age of the elderly participants was 68.39 years in the intervention group and 67.33 years in the control group. A total of $66.7 \%$ of participants were female in the intervention group compared to $57.1 \%$ in the control group. In the intervention group, 30.6\% obtained education at the elementary school level compared to $21.4 \%$ in the control group. A total of $56.9 \%$ of participants were employed in the intervention group compared to $65.7 \%$ in the control group. In the intervention group, $45.8 \%$ received adequate income compared to $38.6 \%$ in the control group. More than half of elderly participants had chronic health conditions including hypertension, diabetes, coronary artery disease, and gout; $58.3 \%$ in the intervention group and $55.7 \%$ in the control group. There were no significant differences in the age $(p=0.373)$, gender $(p=0.300)$, education $(p=0.254)$, income $(p=0.401)$, employment $(p=0.306)$, and health conditions $(\mathrm{p}=0.865)$. It could be that both groups had similar characteristics at baseline.

\subsection{Variables of Interest}

Regarding stress knowledge before the program, both groups had knowledge levels at low, fair, and high (the intervention group $59.7 \%, 32.0 \%, 8.3 \%$, and the control group $58.6 \%, 25.7 \%$, and $15.7 \%$ ) respectively, as shown in Table 2 . After the program and follow-up (3 months), it showed stress knowledge of the intervention group was higher than the control group. When the mean scores between the postintervention and follow-up were compared, the mean knowledge scores of the intervention group were higher than the control group with the significance $(\mathrm{p}<0.05)$ as shown in Table 3.

Table 2 illustrates the changes of variables between the intervention and the control groups. The findings of the intervention group showed that before the program, the majority of stress levels were at fair, low, and high (47.2\%, $41.7 \%, 11.1 \%$, respectively). The control group showed stress levels at fair, low, and high $(51.4 \%, 35.7 \%, 12.9 \%$, respectively). In terms of post-intervention and follow-up, the stress levels of the intervention group had reduced to low and fair levels compared to the control group. When the mean scores between the post-intervention and follow-up were compared, the mean stress level scores of the intervention group had statistically significantly decreased $(\mathrm{p}<0.05)$, as shown in Table 3.

Table 2. Number and percentage of knowledge, stress level, and stress management of participants between intervention and control groups $(\mathrm{N}=\mathbf{1 4 2})$.

\begin{tabular}{|c|c|c|c|c|c|c|}
\hline \multirow{2}{*}{ Variables } & \multicolumn{3}{|c|}{ Intervention Group (n=72) } & \multicolumn{3}{c|}{ Control Group (n=70) } \\
\cline { 2 - 6 } & Pre-test & Post-test & Follow-up & Pre-test & Post-test & Follow-up \\
\cline { 2 - 6 } & $\mathbf{n}(\%)$ & $\mathbf{n}(\mathbf{\%})$ & $\mathbf{n}(\mathbf{\%})$ & $\mathbf{n}(\mathbf{\%})$ & $\mathbf{n}(\mathbf{\%})$ & $\mathbf{n}(\mathbf{\%})$ \\
\hline Knowledge & & & & & & \\
\hline High ( $\geq 8$ scores) & $6(8.3)$ & $26(36.1)$ & $35(48.6)$ & $11(15.7)$ & $14(20.0)$ & $23(32.9)$ \\
\hline Moderate (6-7 scores) & $23(32.0)$ & $36(50.0)$ & $31(43.1)$ & $18(25.7)$ & $28(40.0)$ & $34(48.6)$ \\
\hline Low (0-5 scores) & $43(59.7)$ & $10(13.9)$ & $6(8.3)$ & $41(58.6)$ & $28(40.0)$ & $13(18.5)$ \\
\hline Stress level & & & & & & \\
\hline High ( $\geq 64$ scores) & $8(11.1)$ & $2(2.8)$ & $1(1.4)$ & $9(12.9)$ & $3(4.3)$ & $2(2.9)$ \\
\hline Moderate (49-63 scores) & $34(47.2)$ & $22(30.6)$ & $17(23.6)$ & $36(51.4)$ & $34(48.6)$ & $31(44.3)$ \\
\hline Low (0-48 scores) & $30(41.7)$ & $48(66.6)$ & $54(75.0)$ & $25(35.7)$ & $33(47.1)$ & $37(52.8)$ \\
\hline Stress management & & & & & & \\
\hline High ( $\geq 32$ scores) & $8(11.1)$ & $19(26.4)$ & $29(40.3)$ & $15(21.4)$ & $16(22.9)$ & $19(27.1)$ \\
\hline Moderate (25-31 scores) & $29(40.3)$ & $49(68.1)$ & $40(55.6)$ & $17(24.3)$ & $37(52.9)$ & $37(52.9)$ \\
\hline Low (0-24 scores) & $35(48.6)$ & $4(5.5)$ & $3(4.1)$ & $38(54.3)$ & $17(24.2)$ & $14(20.0)$ \\
\hline
\end{tabular}


Table 3. Comparison the mean score of variables between the intervention and control groups, at baseline, post-intervention and follow-up (3 months) $(\mathrm{N}=142)$.

\begin{tabular}{|c|c|c|c|c|c|c|}
\hline \multirow{2}{*}{ Variable } & \multicolumn{2}{|c|}{ Intervention Group $(\mathrm{n}=72)$} & \multicolumn{2}{|c|}{ Control Group (n=70) } & \multirow{2}{*}{$\mathbf{t}$} & \multirow{2}{*}{ P-value } \\
\hline & mean & S.D. & mean & S.D. & & \\
\hline \multicolumn{7}{|l|}{ Knowledge } \\
\hline Baseline & 5.40 & 1.19 & 5.41 & 1.44 & 0.052 & 0.959 \\
\hline Post-intervention & 6.88 & 1.25 & 6.07 & 1.32 & 3.715 & $0.001^{*}$ \\
\hline Follow-up (3 months) & 7.28 & 1.12 & 6.66 & 1.20 & 3.189 & $0.002 *$ \\
\hline \multicolumn{7}{|l|}{ Stress level } \\
\hline Baseline & 46.17 & 10.28 & 48.47 & 9.34 & -1.397 & 0.165 \\
\hline Post-intervention & 42.53 & 8.26 & 46.01 & 7.65 & -2.609 & $0.010^{*}$ \\
\hline Follow-up (3 months) & 40.82 & 6.82 & 45.00 & 6.83 & -3.649 & $0.000^{*}$ \\
\hline \multicolumn{7}{|l|}{ Stress management } \\
\hline Baseline & 24.78 & 4.87 & 24.60 & 5.82 & 0.198 & 0.844 \\
\hline Post-intervention & 28.24 & 3.91 & 25.63 & 5.58 & 3.323 & $0.002 *$ \\
\hline Follow-up (3 months) & 29.80 & 3.82 & 26.57 & 5.03 & 4.322 & $0.001 *$ \\
\hline
\end{tabular}

\section{* Significance at level 0.05}

Regarding stress management before the program, both groups had stress management levels at low, fair, and high (the intervention group $48.6 \%, 40.3 \%, 11.1 \%$, and the control group $54.3 \%, 24.3 \%$, and $21.4 \%$ ), respectively as shown in Table 2 . In terms of post-intervention and follow-up, it was found that stress management in the intervention group had improved better than in the control group. When the mean scores between the post-intervention and follow-up were compared, the mean stress management scores of the intervention group were higher than the control group with the significance $(\mathrm{p}<0.05)$ as shown in Table 3.

The analysis of repeated measure ANOVA showed a statistically significant difference in the effects of stress management training program on changes in mean scores of stress knowledge, stress level, and stress management among elderly people between the intervention and control groups at baseline, post-intervention, and 3-month follow-up $(\mathrm{p}<0.05)$ as shown in Table 4. For within-subject testing, the GreenhouseGeisser correction was used due to violation of sphericity. The results gave the overall significant effect of stress management training program on changes in mean scores of stress knowledge and stress management over three-time points $(p<0.001)$, whereas the marginally significant effect on changes in stress mean score was found $(p=0.078)$.

Table 4. Repeated measure ANOVA of variables between the intervention and control groups $(\mathrm{N}=142)$.

\begin{tabular}{|c|c|c|c|c|c|}
\hline Variables & SS & df & MS & F-test & P-value \\
\hline \multicolumn{6}{|l|}{ Knowledge } \\
\hline \multicolumn{6}{|l|}{ Between subjects } \\
\hline Intervention & 23.61 & 1 & 23.61 & 7.72 & $<0.006$ \\
\hline Error (between group error) & 428.12 & 140 & 3.06 & & \\
\hline \multicolumn{6}{|l|}{ Within subjects* } \\
\hline Time & 180.21 & 1.77 & 101.57 & 106.49 & $<0.001$ \\
\hline Intervention $\mathrm{x}$ Time & 12.98 & 1.77 & 7.32 & 7.67 & 0.001 \\
\hline Error (Time error) & 236.92 & 248.40 & 0.95 & & \\
\hline \multicolumn{6}{|l|}{ Stress level } \\
\hline \multicolumn{6}{|l|}{ Between subjects } \\
\hline Intervention & 1179.81 & 1 & 1179.81 & 6.41 & 0.012 \\
\hline Error (between group error) & 25766.49 & 140 & 184.05 & & \\
\hline \multicolumn{6}{|l|}{ Within subjects* } \\
\hline Time & 1452.48 & 1.57 & 925.29 & 63.89 & $<0.001$ \\
\hline Intervention $\mathrm{x}$ Time & 62.82 & 1.57 & 40.02 & 2.76 & 0.078 \\
\hline Error (Time error) & 3182.57 & 219.77 & 14.48 & & \\
\hline \multicolumn{6}{|l|}{ Stress management } \\
\hline \multicolumn{6}{|l|}{ Between subjects } \\
\hline Intervention & 428.68 & 1 & 428.68 & 6.47 & 0.012 \\
\hline Error (between group error) & 9280.62 & 140 & 66.29 & & \\
\hline Within subjects* & & & & & \\
\hline
\end{tabular}


(Table 4) contd.....

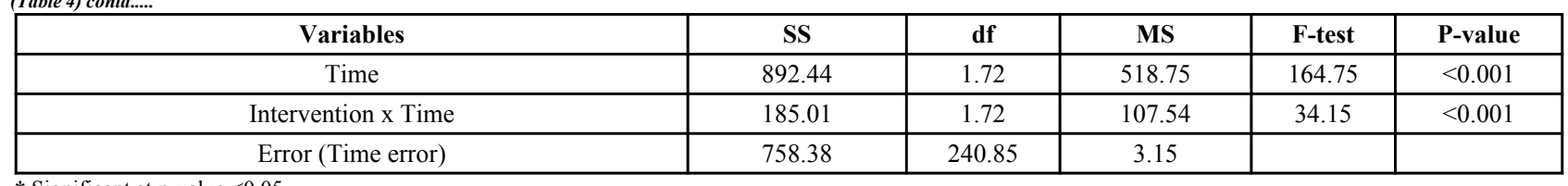

Significant at $p$-value $<0.05$

SS: Sum of Squares, df: Degrees of freedom, MS: Mean Square

\section{DISCUSSION}

The stress management training program on knowledge and skills to manage stress could reduce stress among the elderly. It showed participants in the intervention group had higher knowledge than the control group. Activities and video demonstrations could create awareness regarding stress and stress management among the elderly. The overall program could create awareness and understanding of the knowledge, promote healthy behaviors, and monitor their own risk behaviors, which is consistent with Pender's theory [20]. Pender mentioned that personal factors and perception of information could directly influence the cognitive behavior and emotion of people. It has a direct influence on healthpromoting behavior if people are able to perceive benefits from behavioral practice $[20,30]$. This is consistent with a previous study, which mentioned that when an intervention program is systematically planned with self-action activities, the perceived self-efficacy toward self-care behaviors using Thai traditional medicine in the intervention group will go higher than the control group. The program provides well-planned activities, self-practice using video demonstrations, model representations, and encouragement from peers, and the research team could enhance participants' confidence in performing selfmanagement [30, 31].

In terms of stress management, elders can manage stress correctly and effectively after gaining knowledge and understanding about stress. This is consistent with the concept of self-management, which can be described as that when a person believes he/she can learn new knowledge and apply it in a practical way, they have the motivation to perform self-care behaviors toward health [32]. Meditation practice focused on deep breathing exercises by inhaling and exhaling slowly. When a person concentrates on meditating for 45 minutes continuously, it helps reduce stress and anxiety. This is similar to the previous program interventions, including relationship building, breathing exercise, muscle relaxation practice, and group counselling. The activities helped participants in the intervention group manage stress better and reduce stress and anxiety compared to participants from the control group $(p<0.05)$ [12]. For Thai traditional massage, the activity is the effective form of bodywork for pain relief and relaxation [33, 34]. There are 5 postures demonstrated in the handbook for participants to follow. Participants had to practice once a day (16.00-17.00 pm, 30-45 minutes each session). However, some massage postures may require someone to assist elders in order to prevent falls and to remain safe. After performing the massage, participants could feel relaxation mentally and physically. Moreover, relaxation massage can help with the flow in the circulatory system, reduce muscle tension and stimulate the release of endorphin, which helps reduce stress [34]. The duration of the practice was appropriate for the elderly because it was not too short or too long, so it was easy for them to attend the session. This is consistent with the study that muscle relaxation training and meditation for 45-60 minutes are suitable for older people, and it is appropriate stress management for the elderly $[12,23]$. The steps used in the intervention activity are similar to the study of selfmanagement stress consisting of 4 ways: 1 . Breathing exercise, 2. Progressive muscle relaxation, 3. Autogenic training, and 4. Meditation. The difference in stress scores among participants in the intervention group was found to be statistically significant. When a comparison was made between the groups, elderly participants' stress scores in the intervention group were lower than the control group [33]. Stress management through meditation and relaxation massage are appropriate activities to use among the elderly. Both activities help reducing stress and anxiety and create a conscious mind among elderly people, which is great for performing daily activity [12, $33,34,37]$. A previous study showed statistically significantly lower depression scores of participants in the intervention when compared to the control group $(\mathrm{p}<0.01)$ [34].

In terms of the level of stress, the scores of stress level in the intervention group were decreased than the control group after the program. Participants in the intervention group received the stress training program, including meditation practice and self-practice massage applied from Thai traditional medicine and local wisdom. Meditation practice focused on deep breathing exercises and self-practice massage. This is similar to the study stating that relaxation is the reaction of the body and mind. It restores the body into the normal state [35]. It results in the normal functioning of the body, which reduces the function of the autonomic nervous system, also called the sympathetic nervous system $[35,36]$. When people are under stress, the sympathetic systems are over-functioning, resulting in changes in the body both physically and mentally. The holistic concepts believe that the human body and mind are linked and communicate through chemical reactions within the body. By promoting good health and well-being, relaxation of mind is focused on. This is also consistent with a study showing that headache can result from muscle contraction (tension-type headache) $[15,26]$. It can be found commonly among patients with chronic pain. So traditional Thai massage is one of the options to help relieve pain without taking any drugs $[15,26,33,34,37]$. Moreover, using heat herbal compress ball twice a day in the morning and the evening for about 10-15 minutes each time helps stretching the tissues, reducing muscle contraction, and making a patient feel relaxed [30]. Consistent with a previous study, it was found that after having Thai massage using heat herbal compress ball, participants would feel more relaxed. It was reported there was a statistically significant difference in neck movements of participants in the intervention group compared to the participants in the control group $(\mathrm{p}<0.05)$ after the program $[15,17]$. 


\subsection{Limitation and Recommendations}

First, the elderly may forget to record their daily routine; therefore, research staff had to visit their homes regularly to make sure they could perform self-management and record their performance routinely and effectively. Second, some participants have chronic conditions such as diabetes and hypertension; therefore, they have to be careful about health complications toward practicing a massage. Third, practice medication and breathing exercises were demonstrated by a person; therefore, there should be a video demonstration for the elderly to use for practicing by themselves. Forth, this study was unable to avoid the Hawthorne effect. Finally, this study was conducted in a rural area within the two-sub district from one province located in the northern part of Thailand; therefore, the results may not be generalizable to other areas of study. In terms of recommendation, this study did not involve family members or elderly caretakers. There should be increased support within family members or the community for the elderly to perform self-stress management. Moreover, longterm studies to see changes in self-management and reduction of health complications should be encouraged. Future research should involve qualitative study in order to gain a better understanding of elders' self-management behaviors altogether with the integration of Thai traditional medicine among elderly with chronic health conditions.

\section{CONCLUSION}

The activities, including self-practice massage, stress management, and meditation with deep breathing exercise, help elders relax physically and mentally and promote good health among them. The program was applied from Thai traditional medicine and local wisdom along with the introduction of science in the area of public health. It helps participants cure certain diseases and restore the body to a normal state. The activities included in the intervention involve the virtues and principles of the Buddhist way of life, so a person who performs massage has to be gentle and courteous.

\section{ETHICS APPROVAL AND CONSENT TO PARTI- CIPATE}

The study was approved by the Human Ethics Committee of University of Phayao Thailand (ID \# 2/101/59). The trial was registered at the Thai clinical trials registry (TCTR20200415005).

\section{HUMAN AND ANIMAL RIGHTS}

No animals were used in this research. All human research procedures followed were in accordance with the ethical standards of the committee responsible for human experimentation (institutional and national) and with the Helsinki Declaration of 1975, as revised in 2013.

\section{CONSENT FOR PUBLICATION}

Written informed consent was obtained from each participant prior to the study.

\section{AVAILABILITY OF DATA AND MATERIALS}

The data that support the findings of this study are available on request from the corresponding author [K.S].

\section{FUNDING}

The study is financially supported by the University of Phayao (Grant no RD61059).

\section{CONFLICT OF INTEREST}

The authors declare that there is no conflict of interest, financial, or otherwise.

\section{ACKNOWLEDGEMENTS}

The authors would like to extend their sincere appreciation to the University of Phayao (Grant no RD61059) for the financial support of this research. The authors also express their deepest gratitude to all participants for their contribution to the study.

\section{REFERENCES}

[1] Mohtasham AZ, Farazmand A, Toloei M. Causes of patient's hospitalization in Guilan university hospitals. Majallah-i Danishgah-i Ulum-i Pizishki-i Gilan 2002; 11: 28-32.

[2] Aldrich N, Benson WF. Disaster preparedness and the chronic disease needs of vulnerable older adults. Prev Chronic Dis 2008; 5(1): A27. [PMID: 18082016]

[3] Moradi Z, Far Ajallah Bike Nouri M, Mohammadi M, Esfandnia F, Taovsi P, Esfandnia A. Evaluation of stress factors among the elderly in the nursing homes for the elderly (Eram and Mother) in Kermanshah, in 2015. J Med Life 2015; 8(Spec Iss 3): 146-50. [PMID: 28316682]

[4] Potter PA, Perry AG. Fundamentals of nursing Mosby St Louis Mo: Mosby Elsevier. 2005; pp. 132-8.

[5] Poolsawat A. Change of the elderly Mahidol University International College 2017. Available at: http://www.gj.mahidol.ac.th/th/wpcontent/uploads/conference/2560/ch ange.pdf

[6] National Statistical Office. Elderly statistics report Department of Senior Services, Ministry of Social Development and Human Security, Thailand 2017. Available at: http://www.dop.go.th/download/knowledge/th1533055363-125_1.pdf

[7] National statistical office The population 2018 and housing census Phayao province Social Statistics Bureau, National Statistical Office, Thailand 2018; 45-68.

[8] Department of Mental Health. Strategic plan for the mental health during the national economic and social development plan No 12 (2017-2021). Ministry of Public Health, Nonthaburi Thailand 2017; 111-3.

[9] Phayao Hospital. Report situation of mental health in Phayao Psychiatric services Phayao Hospital 2017. Available at: http://mhc01.net/images/phayao.pdf

[10] Vasunilashorn S, Glei DA, Weinstein M, Goldman N. Perceived stress and mortality in a Taiwanese older adult population. Stress 2013; 16(6): 600-6.

[http://dx.doi.org/10.3109/10253890.2013.823943] [PMID: 23869432]

[11] Lazalus RS, Folkman S. Stress appraisal and coping. New York: Spring 1984.

[12] Kiatsinsap J, Thotong S, Yamboonruang T. Effects of the stress coping program on coping abilities and stress level of the elderly in Mueang Nonthaburi district. Kuakarun J of Nursing 2019; 26: 66-77.

[13] Division of Mental Health Promotion and Development. Social and psychological care guidelines for the elderly to prevent mental health problems Department of Mental Health, Ministry of Public Health, Nonthaburi Thailand 2015. Available at: http://164.115.41.179/promote/sites/default/files/sites/default/files/sw/ 1.pdf

[14] Sharpe PA, Williams HG, Granner ML, Hussey JR. A randomised study of the effects of massage therapy compared to guided relaxation on well-being and stress perception among older adults. Complement Ther Med 2007; 15(3): 157-63.

[http://dx.doi.org/10.1016/j.ctim.2007.01.004] [PMID: 17709060]

[15] Sitikaipong K, Tangsukruthai P, Noothim P, et al. Comparative study 
the efficacy of Thai massage and analgesic drug (Diclofenac) to relief shoulder pain. J of Health Science 2014; 23: 842-84.

[16] Barnes PM, Bloom B, Nahin RL. Complementary and alternative medicine use among adults and children: United States, 2007. Natl Health Stat Rep 2008; 10(12): 1-23.

[PMID: 19361005]

[17] Zahourek RP. Overview: relaxation and imagery tools for therapeutic communication and intervention. Alternative Health Practitioner 1997; 3: 89-92.

[http://dx.doi.org/10.1177/153321019700300206]

[18] Lazar SW, Bush G, Gollub RL, Fricchione GL, Khalsa G, Benson H. Functional brain mapping of the relaxation response and meditation. Neuroreport 2000; 11(7): 1581-5.

[http://dx.doi.org/10.1097/00001756-200005150-00042] [PMID: 10841380]

[19] Ratsamana P. Effect of practicing SKT 1 healing meditation to blood pressure level of essential hypertensive patients in primary care cluster Naimuang municipal district Sawankhalok, Sukhothai province 2018.

[20] Pender NJ. Health Promotion in Nursing Practice. 2nd ed. New York: Appleton and Lange 1987.

[21] Mahatnirunk S. Suanprung stress test 2002.https://www.dmh.go.th/abstract/nurse/details.asp?id=2371

[22] Mahatnirunk S. Suanprung stress test. Thailand: Suanprung Hospital, Department of Mental Health, Ministry of Public Health 2002.

[23] Chotinaiwattarakul W, Nilanon Y, Saengsumat P, et al. The effectiveness of massage to reduce headaches from muscle contraction 2012.https://www.si.mahidol.ac.th/th/division/soqd/admin/assetstar_fil es/18_7.pdf

[24] Glass GV. Primary secondary and meta-analysis of research. Educ Res 1976; 5: 3-8.

[http://dx.doi.org/10.3102/0013189X005010003]

[25] Cohen J. Statistical power analysis for the behavioral sciences. 2nd ed.
Hillsdale, NJ: Lawrence Earlbaum Associates 1988; pp. 7-57.

26] Thai massage guide to health promotion elderly 2009.http://kb.hsri.or.th/dspace/handle/11228/2793?locale-attribute=th

[27] 2014.http://164.115.27.97/digital/files/original/f662088b1 fec03a26d28 d72d54b2928a.pdf

[28] Srithupthai K, Hongsuwan N, Phoomchaichot A, Phromdi P. Herbal formulas developed to reduce maternal postpartum breast engorgement. Sakon Nakhon Rajabhat University J of Science and Technology 2015; 7: 33-9.

[29] Thai royal massage. Bangkok: Pikanate Printing Center Company 2005; pp. 15-60.

[30] Rujiganjanarat K. The effectiveness of Thai massage with Thai yoga exercise for relieves pain of osteoarthritis of the knee in elderly in $\mathrm{Na}$ Wung sub-district, Muang district, Phetchaburi province. Srinagarind Medical J 2018; 33: 339-45.

[31] Sawangwong P, Tansakul S, Therawiwat M. The effect of self-efficacy program on self-care behaviors using Thai traditional medicine in patients with upper back pain at Thai traditional and integrated medicine hospital. J Health Educ 2018; 41: 102-13.

[32] Wattana C. Self-management support: strategies for promoting disease control. J of Phrapokklao Nursing College 2015; 26: 1-11.

[33] Singhada A, Rojpaisankit K, Nokdee S. Effects of stress management program on stress of the elderly. Huachiew Chalermprakiet Science and Technology J 2016; 19: 49-60.

[34] Klungsri P, Aniwattanapong D. Effect of Thai traditional massage for reduction of depression in social welfare development center for older persons. Chulalongkorn Medical Bulletin 2019; 1: 135-46.

[35] Benson H. The relaxation response. New York: Aron Books 1976; pp. 20-89.

[36] Benson H. Mind-body pioneer. Psychol Today 2001; 34: 56-9.

[37] Khotaphan S, Charucharana S. Office syndrome in Thai traditional medicine. Phranakhon Rajabhat Research J 2017; 12: 135-42. [Science and Technology].

\section{C) 2021 Choowanthanapakorn et al.}

This is an open access article distributed under the terms of the Creative Commons Attribution 4.0 International Public License (CC-BY 4.0), a copy of which is available at: https://creativecommons.org/licenses/by/4.0/legalcode. This license permits unrestricted use, distribution, and reproduction in any medium, provided the original author and source are credited. 